\title{
Economic Performance Analysis of Selected Military Hospitals Using Hospital Indicators and Inpatient Bed-Day Cost
}

\author{
Ehsan Teymourzadeh' ${ }^{1}$, Mohammadkarim Bahadori ${ }^{1}$, Mohammad Meskarpour-Amiri ${ }^{1}$, Javad \\ Khoshmanzar ${ }^{1}$, Sayyed-Morteza Hosseini-Shokouh ${ }^{1,2^{*}}$ \\ ${ }^{1}$ Health Management Research Center, Baqiyatallah University of Medical Sciences, Tehran, Iran \\ 2Department of Health Services Management, Faculty of Health, Baqiyatallah University of Medical Sciences, Tehran, \\ Iran
}

*Corresponding Author: Sayyed-Morteza Hosseini-Shokouh, Ph.D., Assistant Professor, Faculty of Health, Baqiyatallah University of Medical Sciences, Tehran, Iran. Tel: +98-21-82483524, Email: hosainysh.morteza@gmail.com

Received September 3, 2018; Accepted January 27, 2019; Online Published January 30, 2019

\begin{abstract}
Background: Hospitals, the main providers of healthcare services, are costly centers which account for about $80 \%$ of the health sector budget and have a huge share of resources.

Objective: This study aimed to analyze the economic performance of selected military hospitals in Tehran using hospital indicators and inpatient bed-day costs.

Methods: This descriptive, cross-sectional, retrospective study conducted in hospitals affiliated with a military medical university. Data was collected with forms completed by referring to the hospitals' finance and accounting, medical records, staffing, and logistics departments. The extracted data converted to hospital indicators using the appropriate formulas and analyzed using Excel and SPSS software with the T-test.

Results: The average bed occupancy rate (BOR) was $71 \%$, the average length of stay (ALOS) was 2.5 days, the average bed turnover (BT) was 31 times, and the average bed turnover interval (BTI) was one day. The comparison of means of all the above-mentioned indicators other than BOR with the national standards was statistically significant $(P<0.05)$. Inpatient bedday costs with and without capital costs were calculated to be 3312353 IRR and 12253775 IRR, respectively.

Conclusion: Higher BOR and BT and lower ALOS and BTI indicators were appropriate compared with the national standards, but the cost performance was not appropriate. An unreasonable increase in inpatient bed-day cost revealed that there were unused beds and that hospitals had no monitoring systems for revenues and expenditures. Therefore, serious attention must be given to the scientific criteria and principles of health economics to improve resource productivity.

Keywords: Hospital Costs, Military Hospitals, Healthcare Indicators
\end{abstract}

\section{Background}

Hospitals are the largest healthcare providers in the community. The demand for healthcare services is increasing, and thus, hospitals are considered important yet extremely costly organizations. ${ }^{1,2}$ The statistics confirmed that treatment and hospital sectors account for $50 \%-80 \%$ of the health sector's financial resources in developing countries. ${ }^{3}$ However, the share of hospital costs from health and treatment in the public sector does not exceed $40 \%$ in developed countries. Unfortunately, more than $80 \%$ of these declining resources are allocated to hospitals in which the efficiency is less than $50 \%$ of the capacity in developing countries., ${ }^{4,5}$ Today, considering the increased number and variety of medical technologies and the increasing demand for new services, increases in the cost of healthcare services provision are inevitable. ${ }^{6}$ The levels of efficiency and productivity are reduced, and a loss of capital and lack of labor are present in developing countries where issues related to the supply of capital and human resources are associated with nonutilization of existing equipment resulting from work and administrative practices. ${ }^{4}$ One main problem in providing healthcare services is the issue of economics, and hospitals comprise one of the most important economic units in the healthcare of any country; thus, it seems reasonable that an important part of economic studies related to healthcare services should focus on such unit. The main reason to use scientific and practical methods in assessing hospital performances and activities is to optimize the utilization of available physical and human resources, and this has

Copyright (C 2019 The Author(s). This is an open-access article distributed under the terms of the Creative Commons Attribution License (http:// creativecommons.org/licenses/by/4.0), which permits unrestricted use, distribution, and reproduction in any medium, provided the original work is properly cited. 
become the goal of managers and planners in hospitals. ${ }^{1,7}$ Hospital statistics and indicators are criteria for measuring the success of a hospital organization and determining the level of achievement of desired goals. It can be said that the improvement of hospital indicators means the efficiency and effectiveness of hospital activities, or, in other words, the proper performance of personnel and the optimal utilization of resources. ${ }^{8}$ Experts consider bed-day cost, bed occupancy rate (BOR), average length of stay (ALOS), bed turnover (BT), and bed turnover interval (BTI) as the most important economic indicators for assessing hospital performance. The fact is that there are no detailed studies on inpatient bed-day cost to estimate treatment fees, while two of the most important factors in determining fees is inpatient bed-day cost and hoteling. ${ }^{7}$ Previous studies have referred to factors such as high ALOS, low BOR, and low BT rates as the reasons for high costs, especially bed-day costs. For example, results of a study carried out in selected hospitals of Iran University of Medical Sciences referred to the increase in inpatient bed-day cost, ALOS, the average $\mathrm{BTI}$, and the low BOR and BT as the main reasons for inefficiency and non-effectiveness and, ultimately, the nonoptimal utilization of resources in the studied hospitals. ${ }^{7}$ Shepard et al also concluded in studies in the United States that every country should design and implement costing strategies and its own methods for analyzing hospital costs based on managerial needs and accessibility to necessary information. ${ }^{9}$ Another important point is that the elevated cost of healthcare services today has led public and private healthcare systems to show more willingness to conduct applied health economics studies ${ }^{10-12}$ and even consider health economists as advisers and an integral part of the healthcare team. ${ }^{10}$

\section{Objective}

Considering that hospitals, especially military ones, are the most important components of healthcare centers and that less focus has been placed on inpatient bed-day costs, specifically in military hospitals, such studies seem necessary so that it is possible not only to plan services in budgeting, but also to compare the efficiency of various services, pricing, and prioritizing various services. Therefore, the present study was carried out to evaluate the economic performance of selected military hospitals in Tehran using performance indicators and inpatient bedday costs.

\section{Methods}

The present research is a descriptive-analytic study with a cross-sectional, retrospective one-year design that was conducted on 3 military hospitals in Tehran. Efforts were made to evaluate data related to hospital performance indicators and bed-day costs before 2016. In the first phase, appropriate information forms with which to collect cost information were prepared based on the opinions of experts and colleagues. In the next phase, information was collected on the calculation of BOR, ALOS, BT, BTI, and components for calculating the mentioned indicators (number of beds constructed and inpatient bed count, total daily census of hospitalized patients, number of discharged patients, number of deaths before and after 24 hours, and number of those transferred from the wards) using a questionnaire the content validity of which was approved in previous studies. ${ }^{8}$ At the beginning of the first phase, information gathering was taught to the questioner, and data collection was carried out after the necessary permissions were obtained and activities were coordinated with the relevant departments in the studied hospitals. Data was collected using information forms available at the hospitals and by referring to financial and accounting, medical records, staff, and logistics departments. The data was then converted into indicators using appropriate formulas. Finally, the collected data was first recorded in Office Excel software and next transferred to SPSS software, and relevant analyses were then carried out. The means of hospital indicators (BOR, ALOS, BT, and BTI) were compared using the one-sample T-test based on the standards presented by the Ministry of Health and Medical Education of Iran. The following formula was used to calculate the inpatient bed-day cost:

Inpatient bed-day cost $=$ Development and capital costs Total hospital costs/Total inpatient days

The studied hospitals were referred to as A, B, and C in order to observe ethical principles and confidentiality.

\section{Results}

The results indicated that the value of BOR in Hospital A during the 12-month period studied ranged from $58.36 \%$ (March) to $86.98 \%$ (April) with an average of $79.16 \%$ $(\mathrm{SD}=7.30 \%)$. The studied hospitals ranked in order of highest to lowest average BOR were A, C, and B. In hospital A during the 12-month study period, ALOS varied from 3.30 days (July) to 3.68 days (February), with a mean of 3.47 days $(\mathrm{SD}=0.12 \%)$. The studied hospitals ranked in order of highest to lowest ALOS were A, B, and C. In hospital $\mathrm{C}$ within the 12-month period, BT ranged between 36.88 times (June) and 45.89 times (April), with an average of 41.39 times $(\mathrm{SD}=3.10)$. The hospitals ranked in order of highest to lowest average BT were hospitals $\mathrm{C}, \mathrm{B}$, and A. The results of the present study showed that the average values of BOR, ALOS, BT, and BTI of the studied hospitals were $71.42 \%, 2.47$ days, 30.86 times, and 0.98 days, respectively. In addition, the difference in average BOR between hospitals was small compared to the Ministry of Health standards, and it was not statistically significant $(P>0.05)$; however, significant differences between the above hospitals and standards of the Ministry of Health were observed in ALOS, BT, and BTI $(P<0.05)$ (Table 1).

In the studied hospitals, a total of 365607254139 IRR was paid for personnel costs (i.e. salaries, benefits, overtime, and fee-for-services (FFS) of official staff; physicians' FFS, salaries, benefits, and overtime of contracted staff), with hospital A paying the highest personnel costs (254589678 172 IRR) and hospitals C and B paying the 
Economic Performance Analysis of Selected Military Hospitals

Table 1. Mean and standard deviations related to BOR, ALOS, BT, and BTI of studied hospitals

\begin{tabular}{|c|c|c|c|c|c|c|c|c|c|c|c|}
\hline \multirow{2}{*}{ Hospital/Indicator } & \multicolumn{2}{|c|}{ Hospital (A) } & \multicolumn{2}{|c|}{ Hospital (B) } & \multicolumn{2}{|c|}{ Hospital (C) } & \multicolumn{2}{|c|}{ Total } & \multirow[t]{2}{*}{ Standard } & \multirow{2}{*}{ t-value } & \multirow{2}{*}{$P$ Value } \\
\hline & Mean & SD & Mean & SD & Mean & SD & Mean & SD & & & \\
\hline BOR & 79.16 & 7.30 & 62.37 & 8.13 & 72.85 & 5.48 & 71.42 & 9.90 & $>70$ & 0.849 & 0.402 \\
\hline ALOS & 47.3 & 0.12 & 13.2 & 0.10 & 76.1 & 0.10 & 47.2 & 0.75 & $<3.5$ & -8.06 & 0.0001 \\
\hline BT & 22.83 & 2.39 & 29.24 & 3.71 & 41.39 & 3.10 & 30.86 & 8.28 & $>24$ & 4.90 & 0.0001 \\
\hline BTI & 0.96 & 0.53 & 1.31 & 0.53 & 0.64 & 0.15 & 0.98 & 0.51 & $<2$ & -11.77 & 0.0001 \\
\hline
\end{tabular}

second and third highest amounts, respectively. The results showed that a total of 330887936004 IRR was paid for consumable (non-personnel) costs (medical and nonmedical supplies, food, fuel, repair, and maintenance) and utilities. Hospital A paid thehighestamount (155730 449337 IRR), with hospitals $\mathrm{C}$ and $\mathrm{B}$ paying the second and third highest amounts, respectively. In the hospitals under study, an estimated 111675578529 IRR was calculated as the depreciation cost of medical equipment and the building. Hospitals A and B experienced the highest and lowest capital expenditures, respectively. The total cost of the studied hospitals was 808170768672 IRR, with hospitals $A$ and B accounting for the highest cost of 462890319320 IRR (57.28\%) and the lowest cost of 130163333385 IRR (16.11\%), respectively. Personnel costs accounted for $45.24 \%$ of the total costs. Personnel costs at the individual hospitals accounted for $55 \%, 41.49 \%$, and $26.5 \%$ of the total costs at hospitals A, B, and C, respectively. Non-personnel costs also accounted for $40.94 \%$ of the total costs in all 3 hospitals. Non-personnel costs at the individual hospitals accounted for $55 \%, 33.65 \%$, and $67.64 \%$ of the total costs in hospitals $\mathrm{C}, \mathrm{A}$, and B, respectively. Capital expenditures accounted for $13.82 \%$ of the total costs in all 3 hospitals; such expenditures accounted for $11.35 \%, 14.84 \%$, and $18.5 \%$ of the total costs at hospitals A, B, and C, respectively. The results showed that the inpatient bed-day cost was 3,312,353 IRR without calculating capital expenditures in each studied hospital. This indicator had the highest and the lowest values in hospitals B (4415344 IRR) and C (1 431129 IRR), respectively. The inpatient bed-day cost was figured to be 12253775 IRR by calculating capital expenditures in the studied hospitals. The highest and lowest bed-day cost was reported in hospital C (16180 149 IRR) and hospital A (2674561 IRR), respectively (Table 2).

\section{Discussion}

The results of the present research revealed that the average BOR, ALOS, BT, and BTI in the studied hospitals was $71.42 \%, 2.47$ days, 30.86 times, and 0.98 days, respectively, which are reasonable and optimal in comparison with the Ministry of Health standards. ${ }^{13,14}$ Ebadi-Fard and Rezapour also reported BOR, ALOS, BT, and BTI values of 57\%, 6 days, 31 times, and 4.5 days, respectively. ${ }^{7}$ In a study by Sadeghifar et al, these indicators were $66.12 \%, 2.92$ days,

Table 2. Calculation of Cost Indicators in the Studied Hospitals (costs are presented in IRR)

\begin{tabular}{lcccc}
\hline Component & Hospital (A) & Hospital (B) & Hospital (C) & Total \\
\hline Number of constructed beds & 694 & 153 & 52 & 899 \\
\hline Number of inpatient beds & 599 & 111 & 50 & 760 \\
\hline Occupied bed-day & 172922 & 25106 & 12244 & 210272 \\
\hline Personnel costs & 254589678172 & 54008567170 & 57009008797 & 365607254139 \\
\hline Non-personnel costs & 155730449337 & 56843071700 & 118314414967 & 330887936004 \\
\hline Capital costs & 52570191811 & 19311964515 & 39793692203 & 111675578529 \\
\hline Total hospital costs & 462890319320 & 130163333358 & 215117115967 & 808170768672 \\
\hline Percentage of personnel costs to total costs & 55 & 41.49 & 26.5 & 45.24 \\
\hline Percentage of non-personnel costs to total costs & 33.65 & 43.67 & 55 & 40.94 \\
\hline Percentage of capital cost to total costs & 11.35 & 14.84 & 18.5 & 13.82 \\
\hline Personnel cost to occupied bed-day ratio & 1472280 & 2151221 & 4656077 & 1738714 \\
\hline Non-personnel to occupied bed-day ratio & 900582 & 2264122 & 9663052 & 1573618 \\
\hline Capital cost to occupied bed-day ratio & 304011 & 769206 & 3250056 & 531100 \\
\hline Personnel costs to constructed beds ratio & 366843916 & 352997171 & 1096327092 & 406682151 \\
\hline Non-personnel cost to constructed beds ratio & 2243954601 & 371523344 & 2275277210 & 368062220 \\
\hline Capital cost to constructed beds ratio & 75749555 & 126220225 & 765263311 & 124222000 \\
\hline Personnel costs to inpatient beds ratio & 425024504 & 486563668 & 1140180175 & 481062176 \\
\hline Non-personnel cost to inpatient beds ratio & 259984055 & 512099745 & 2366288299 & 435378863 \\
\hline Capital cost to inpatient beds ratio & 87763258 & 173979229 & 795873844 & 146941550 \\
\hline Inpatient bed-day cost (without taking into account capital costs) & 2372862 & 4415344 & 1431129 & 3312353 \\
\hline Inpatient bed-day cost (taking into account capital costs) & 2674561 & 5151065 & 16180149 & 15553775 \\
\hline
\end{tabular}


87.82 times, and 2.02 days, respectively. ${ }^{14}$ Amerioun et al reported that these indicators in a military hospital were $79.18 \%, 3.47$ days, 22.83 times, and 0.96 days, respectively. ${ }^{8}$ The results of a study on public and private hospitals affiliated with Tehran University of Medical Sciences reported an average BOR of $66.67 \% .{ }^{15}$ Results of another study on hospitals affiliated with Shahid Beheshti University of Medical Sciences showed that over $86 \%$ of them had a BOR value equal to or less than $80 \% .{ }^{16}$ In a study on intensive care units in the United Kingdom, Jacob et al reported that the average BOR and ALOS in the studied wards was $79 \%$ and 4.41 days, respectively. ${ }^{17}$ According to international standards, the most appropriate BOR in most hospitals is considered to be between $85 \%$ and $90 \%$, with the remaining $10 \%$ to $15 \%$ including beds undergoing repairs, bed changes, and general preparation for subsequent patients. ${ }^{7}$ In the present study, the BOR values in hospitals $\mathrm{A}, \mathrm{C}$, and B were $5 \%-10 \%, 12 \%-17 \%$, and $22 \%-27 \%$ higher than the standards, respectively. A high BOR value indicates excessive pressure and utilization of services, which is likely to result in reduced quality of care. A low BOR value, however, indicates underutilization of the facilities. BOR is typically lower in small hospitals than in large hospitals. To ascertain the burden of activity in hospital wards, BOR must be determined in terms of measurements, specializations, and units. ${ }^{18}$ Experts consider the following factors to be effective in lowering BOR values: (a) lack of specialist staff; $(b)$ lack of adequate funding for recruitment of specialist staff and the inappropriate management of hospitals; (c) lack of full productivity of hospital beds due to poor budget program, since budget estimates are often not based on actual costs, which in turn seriously affects the healthcare sector's programs; and $(d)$ cases such as job dissatisfaction, lack of a referral system, lack of coordinated patient distribution in the hospital, the provision of non-competitive services, non-allocation and combining of resources, problems in earning dedicated revenue, imbalance between supply and demand for inpatient treatment services, and incidence and prevalence changes in different seasons of the year and different regions of the country. ${ }^{18}$

The ALOS indicator in hospital A was about 3.5 days; a value up to the maximum of four days can be justified based on the relevant standards. ${ }^{19}$ However, additional research would allow the realization of ways to reduce ALOS in this hospital by reviewing the admission-discharge process, comparing treatment and clinical measures for patients with national and international standards, studying the causes of readmission to hospital, imposing unnecessary treatments on patients, reducing medical errors, etc. ALOS values that are higher or lower than the optimal levels indicate unnecessary, hasty admissions and negligence in diagnosis and treatment, which would, in any case, result in increased hospital costs. This indicator is also affected by the following factors: (a) Patient characteristics of gender, age, socioeconomic and educational status; $(b)$ characteristics of the disease (some diseases may require a longer hospital stay); (c) hospital characteristics (the ALOS is greater in educational hospitals than in other hospitals, and inappropriate admission and discharge procedures would affect it). ${ }^{7}$ In most public hospitals that accept acute patients, the ALOS varies between 8-15 days. Lowering this indicator from 15 days to 10 days in a 500-bed hospital means that the hospital can serve 6000 additional patients over a year. ${ }^{18}$ In their article on the performance of hospitals in the state of New York, McDermott and Stoke emphasized ALOS from among a set of operational and production management indicators in a hospital, because they believed that it is a key performance indicator and reflects many of the operational dimensions of the hospital organization. ${ }^{20}$ Previous studies have also indicated that this indicator is related to cost, efficiency, quality of care, and the speed of service provision. ${ }^{21-24}$ Therefore, this indicator can be considered as a generally appropriate indicator for measuring performance. McDermott and Stoke referred to this indicator as a tool for measuring the overall organizational performance of a hospital, especially from a strategic perspective. ${ }^{20}$ To confirm the veracity of their view, they referred to the fact that many researchers in hospital affairs have used it widely in their research as an important tool that reflects multiple dimensions of performance such as costs, ${ }^{22,23,25}$ quality, ${ }^{21}$ efficiency, ${ }^{24}$ and profitability. ${ }^{26-33}$ The majority of studies have referred to low ALOS levels as optimal performance levels, ${ }^{21,26,33}$ because they lead to faster treatment and discharge, better resource efficiency, and lower costs. ${ }^{21,34}$ Different opinions have been expressed on the relationship between the ALOS indicator and quality of care ${ }^{20}$; however, the results of a comprehensive experimental study on 13 different types of diseases showed that lower levels of this indicator were related to better quality. ${ }^{21}$ Based on the aforementioned findings and a study by McDermott and Stoke, the ALOS indicator is related to different dimensions of performance, and therefore, can be used as a comprehensive and valid indicator for measuring hospital performance. ${ }^{20}$

Hospitals C, B, and A were ranked first to third for BT indicator, respectively. The nature of specialty activities in hospital $\mathrm{C}$ may lead to a more significant increase in the BT of this hospital than the other two, but the differences between hospitals A and B compel further study to determine the underlying cause of their low BT values, especially that of hospital A. It should not be forgotten that the above indicator is related to other performance indicators, especially the BOR indicator. There is always a reverse relationship between the $\mathrm{BOR}$ and $\mathrm{BT}$ indicators. If the opposite is seen in the hospital chart and statistics, there can be doubts about the accuracy of information; however, there is no logical relationship between these indicators and ALOS. There is also a direct relationship between ALOS and BOR. An interesting point about the relationship between $\mathrm{BOR}$ and $\mathrm{BT}$ indicators is that if ALOS is constant at a certain time, even if BT increases, BOR will decrease. There is often a reverse relationship between the $\mathrm{BOR}$ rate and $\mathrm{BT}$ indicators, and they are directly related to 
each other only when BOR is above $75 \% .^{13}$

BTI values ranked from highest to lowest were seen in hospitals $\mathrm{C}, \mathrm{A}$, and $\mathrm{B}$, respectively. It should be noted, however, that this indicator is closely related to other performance indicators. ${ }^{18}$ The higher BTI is in a hospital, the lower the value of BOR and per-bed admission ratio will be, which will ultimately increase bed-day costs. Generally, an increase in BTI will lead to an increase in empty beds per day and, consequently, impose more costs upon the hospital.

In general, hospital indicators show the performance of a hospital in various fields. Therefore, it is essential to pay thorough attention to these indicators. As the most important factors showing hospital performance, they should also be regularly evaluated and compared over certain time periods. ${ }^{13}$ According to Kunders, the use of hospital indicators such as ALOS, BT, and BOR can be effective in productivity and quality of service. ${ }^{35}$ Moreover, by examining BOR, ALOS, BT, and BTI indicators, the performance of managers and organizations such as a hospital can be evaluated for efficiency. Hospital efficiency can be considered optimal when the values of the BOR and BT indicators are high and those of ALOS and BTI are low. ${ }^{8}$ Therefore, BOR and BT are positive efficiency indicators, and average BTI and ALOS are negative efficiency indicators.

As the results showed, the inpatient bed-day total cost for all hospitals was 3312353 IRR when disregarding capital costs and 12253775 IRR when taking capital costs into account. These amounts are significantly higher than those obtained in other studies, which may be attributed chiefly to the secular inflation in the country. In support of this theory, a 2002 study in hospitals affiliated with Iran University of Medical Sciences showed the average inpatient bed-day cost to be $713000 \mathrm{IRR}^{7}$ when taking capital costs into account.

Based on the inpatient bed-day cost disregarding capital costs, the hospitals ranked from highest to lowest capital costs were hospitals B, A, and C. Therefore, the performance of hospital $\mathrm{C}$ was better than that of the other 2 hospitals. One reason for this difference can be stated as the maximum use of the bed capacity in this hospital, or the performance indicator of the inpatient-bed to constructedbed ratio, because the values for this indicator in hospitals $\mathrm{A}, \mathrm{B}$, and $\mathrm{C}$ were $86.31 \%, 72.54 \%$, and $96.15 \%$, respectively. Other reasons include a higher BT and lower BTI at this hospital in comparison with the other two hospitals, which resulted in the maximum use of available bed capacity and was indirectly effective in reducing the average inpatient bed-day cost. However, the interpretation of this finding should be based not only on quantitative factors and aspects, but also on qualitative factors and aspects such as the type of hospital specialty, the type and combination of patients referred, the quality of treatment, etc.

The results of calculating the cost of inpatient bedday while taking capital costs into account showed that hospitals ranked from highest to lowest capital costs were $\mathrm{C}, \mathrm{B}$, and $\mathrm{A}$, respectively. Thus, the performance of hospital A can be said to be better compared with the other 2 hospitals. Because the capital costs are calculated in this case, this group of costs is mainly considered fixed costs; therefore, by increasing the number of beds and the number of occupied beds, the fixed costs are divided. Thus, the cost effectiveness is expected to increase in this aspect, as costs decrease with increases in the number of beds and number of occupied beds, which is true for the hospitals in question. Moreover, as the results show, hospital A had a higher number of beds and number of occupied bed-days than the other 2 hospitals. The above interpretation can, to a large extent, be confirmed if the percentage of capital costs to total costs as well as the ratios of capital cost to occupied bed-day, number of constructed beds, and inpatient beds are considered in the studied hospitals. The percentage of personnel, non-personnel, and capital costs in all hospitals was calculated to be $45 \%, 41 \%$, and $14 \%$, respectively. Rezapour et al showed in their study that personnel and non-personnel costs accounted for $62 \%$ and $38 \%$ of total operating costs, respectively, in the studied hospitals. ${ }^{36}$ In another study conducted at Qazvin University of Medical Sciences in 2009, the average financial burden imposed on the centers for each inpatient bed-day was estimated to be 345707 IRR. The research findings showed that in educational hospitals, personnel costs account for $67 \%$, and non-personnel and capital costs together account for $33 \%$ of the total current operating costs. ${ }^{37}$ In a study on 495 admissions in the ICU of a pediatric hospital in Madrid, Garcia et al showed that the average fixed daily cost per patient was US\$608, of which $86.3 \%, 9.3 \%$, and $4.4 \%$ belonged to personnel, consumable, and construction and capital costs, respectively. The researchers finally concluded that personnel costs accounting for $62.4 \%$ of total costs were the biggest factor in increasing the costs of care. ${ }^{19}$ In a study in ICUs in the United Kingdom, Jacob showed that the average daily cost per patient was $£ 995 .^{17}$ While pointing out in their article that administrative costs are an important part of hospital costs, McKay et al stated that such costs can have a significant effect on hospital performance. They also stated that there are few studies and, thus, little information regarding these costs. Therefore, they studied these changes in a 5-year period (2000-2004) using administrative costs of acute hospitals in California. The results of their study showed that the aforementioned costs increased from 22 million to 28 million dollars on average after inflationary adjustment, while the percentage of administrative costs to total operating costs remained constant at about $23 \%$ during each of the 5 years. They also stated that administrative costs, as a percentage of total operating costs, were far higher in smaller hospitals than in larger hospitals. ${ }^{38}$ Managers seem to be able to reduce inefficiencies in hospital costs by correcting simple management practices. Overall, the studied hospitals do not have optimal conditions in terms of cost performance. However, at least two points should be kept in mind while comparing the findings: 
(A) Time serves as an effective component concerning the cost issue; thus, it is necessary to consider inflation adjustments while comparing the findings, because prices are expected to increase over time. Moreover, the value of a single unit is higher in the present time than its value in the future; thus, the inflation factor should be adjusted and then compared in order to make a real comparison.

(B) In the present study, it was not possible to separate outpatient costs from inpatient costs due to the lack of accurate and appropriate financial and accounting information. Perhaps one reason for the high average inpatient bed-day cost in the present study as compared with that in other studies is the same issue, which is one of the limitations of the present study. Experts and researchers believe that many public hospitals do not pay attention to the bed-day cost. It is not yet clear what performance many hospitals have considering a given amount of funds, human resources, and capital. Whether or not this performance shows a positive balance sheet per funds is also a question? The difference between hospitals with identical and similar conditions in terms of bed-day cost and the significance of this difference are also not clear. ${ }^{7}$ In many hospitals, determining the cost of a bed day does not find its objective reality, and many hospitals still do not know what to do with the funds spent. This is especially neglected in public hospitals due to the provision of funding from the government budget. In other words, the high costs and low income experienced by hospitals in this sector and the subsequent income-expense gap have led to the loss of the capability of most public hospitals to reach the break-even point. ${ }^{39}$

As a general conclusion about the findings reported herein, it should be noted that the high BOR and BT on one hand and low ALOS and BTI on the other confirmed the optimal performance indicators of the hospitals in the current study in comparison with the standards set by the Ministry of Health; however, differences do exist between the Ministry of Health standards and the hospitals in this study in indicators such as BOR and bed BT. Therefore, the following policy suggestions can be presented:

(A) Further studies should be conducted in Hospital B to identify the cause of the BOR indicator in this hospital being lower than the national standard and implement the necessary measures to increase its value. Although the BOR value in the studied hospitals is moderately within the scope of the national standard, it should be noted that in developed countries, as in the members of the Organization for Economic Cooperation and Development (OECD), the BOR value is between $80 \%$ and $85 \%{ }^{40}$ Thus, this issue should be the subject of additional studies order to scientifically determine the cause of the decline in the above indicator.

(B) Additional studies must be conducted at hospital A to scientifically determine the cause of the decline in the BT indicator compared with the other two hospitals as well as the national standard and to implement the necessary measures to increase it.
Research Highlights

\section{What Is Already Known?}

Costing and cost analysis is important from microeconomic prospective in hospital management. Now, the identification, monitoring and management of cost is inevitable to make the right decisions.

\section{What This Study Adds?}

There is no standard for the minimum or maximum of bed-day cost, but it is a good indicator for comparing hospitals cost performance with the same conditions.

Cost performance is not desirable in the studied hospitals. The irrational increase in the cost of a bed day indicated there was an unused bed capacity, lack of financial information, and lack of monitoring of the hospital's revenues and expenditures. In sum, the executive agency failed to manage and neglected health economics criteria. The bed-day cost is the basis for calculating the macrobudget of treatment centers at the national level. Therefore, to calculate realistic fees for medical services and thus the realistic copayments, it is significant importance to determine the daily bed-day fee. It is possible to decreases the inpatient bed-day cost and move the hospital towards the break-even point by making correct decisions, allocating appropriately the hospital resources, and by increasing managers' level of knowledge about performance indicators and directing their thinking toward improving them.

\section{Conclusion}

In general, the high inpatient bed-day cost, low bed constructed to inpatient bed ratio compared to the standard level (95\%), low BOR and BT values in international comparisons, and in short, the weaker performance and lower efficiency indicators in the hospitals in question indicate the under-utilization of available resources. Thus, managers of the studied hospitals need to take urgent measures to identify the factors affecting the dramatic increase in costs and decreases in performance indicators. To this end, determining and evaluating unnecessary hospital admissions is a practical recommendation, because according to the results of global research, a significant number of hospital admissions are unnecessary, which indicates the under-use of hospital beds. Furthermore, management and the calculation of the utilization coefficient is a method used to study the utilization of resources and hospitals beds and to improve them.

\section{Authors' Contributions}

All authors contributed equally in this study.

\section{Conflict of Interest Disclosures}

The authors declare that they have no conflicts of interest. 


\section{Ethical Approval}

The research has been approved by the BMSU's Ethics Committee (No: IR.BMSU.REC.1396.685).

\section{Acknowledgments}

The authors would like to express their appreciation to all personnel working in the selected military hospitals, especially the staff of the financial, accounting, contracting affairs, program and planning, medical records, and the Deputy/Management of Education and Research departments who helped the researchers in this study. It should be noted that the present research project was approved by the Health Management Research Center of Baqiyatallah University of Medical Sciences with the code of 91-373. The efforts and support of Education and Research Management of the Research Center and the Vice Chancellor for Research of BMSU are gratefully acknowledged.

\section{References}

1. Nasiriad N, Rashidian A, Joodaki H, Akbari Haghighi F, Arab $M$. Assessing issues and problems in relatioship between basic insurance organizations and university hospitals: a qualitative research. J Hosp. 2010;9(1-2):5-18. [Persian].

2. Najibi $M$, Dehghan $H$, Jafari $A$, Hoseinpour T, Rezaee R. A study of the problems between basic insurance organizations and teaching hospitals of Shiraz University of Medical Sciences as viewed by the staff of income hospitals and representative of the insurer's organization in 2013. Journal of Health Management and Informatics. 2015;2(3):82-88.

3. Hadian M, Mohammadzadeh A, Imani A, Golestani M. Analysis and unit cost estimation of services using "StepDown Method" in Fatemieh Hospital of Semnan University of Medical Sciences-2006; Iran. Journal of Health Administration. 2009;12(37):39-48. [Persian].

4. Barnum H, Kutzin J. Public hospitals in developing countries: resource use, cost, financing. Baltimore: Johns Hopkins University Press; 1993.

5. Jacobs P, Rapoport J. The economics of health and medical care. Massachusetts: Jones \& Bartlett Learning; 2004.

6. Lieu T, Messonnier ML, Meltzer MI. Guidance for health economics studies presented to the Advisory Committee on Immunization Practices (ACIP). Atlanta: Centers for Disease Control and Prevention; 2008.

7. Ebadi F, Ansari H, Rezapoor A. Study of daily bed occupancy costs and performance indexes in selected hospital at of Iran University of Medical Sciences in 2002. Journal of Health Administration. 2005;7(18):37-44. [Persian].

8. Amerioun A, Hosseini Shokouh SM, Karimi Zarchi AA, Mahmoudi N. Hospital manager's leadership style from staffs viewpoint and its relationship with hospital indicators. J Mil Med. 2011;13(3):125-132.

9. Shepard DH, Hodgkin D, Anthony Y. Analysis of hospital costs: a manual for managers. Geneva: World Health Organization; 2000.

10. Meltzer MI. Introduction to health economics for physicians. Lancet. 2001;358(9286):993-998. doi:10.1016/s01406736(01)06107-4.

11. Meltzer MI. Health economics and prioritising health care. Lancet. 2008;372(9639):612-613. doi:10.1016/s01406736(08)61257-x.

12. Weinstein MC, Skinner JA. Comparative effectiveness and health care spending--implications for reform. N Engl J Med.
2010;362(5):460-465. doi:10.1056/NEJMsb0911104.

13. Jonaidi Jafari N, Sadeghi M, Izadi M, Ranjbar R. Comparison of performance indicators in one of hospitals of Tehran with national standards. J Mil Med. 2011;12(4):223-228.

14. Sadeghifar J, Ashrafrezaee N, Hamouzadeh P, Taghavi Shahri M, Shams L. Relationship between performance indicators and hospital evaluation score at hospitals affiliated to Urmia University of Medical Sciences. J Urmia Nurs Midwifery Fac. 2011;9(4):270-276. [Persian].

15. Hosseini Shokouh S, Arab M, Rahimi A, Rashidian A, Sadr Momtaz N. Preparedness of the Iran University of Medical Sciences hospitals against earthquak. Journal of School of Public Health and Institute of Public Health Research. 2009;6(3):61-77. [Persian].

16. Hosseini Shokouh SM, Anjomshoa M, Mousavi SM, et al. Prerequisites of preparedness against earthquake in hospital system: a survey from Iran. Glob J Health Sci. 2014;6(2):237245. doi:10.5539/gjhs.v6n2p237.

17. Jacobs P, Rapoport J, Edbrooke D. Economies of scale in British intensive care units and combined intensive care/high dependency units. Intensive Care Med. 2004;30(4):660-664. doi:10.1007/s00134-003-2123-2.

18. Sakharkar BM. Principles of hospital administration and planning. New Delhi: Jaypee Brothers Medical Pub; 2008.

19. Garcia S, Ruza F, Alvarado F, et al. Analysis of costs in a pediatric ICU. Intensive Care Med. 1997;23(2):218-225. doi:10.1007/s001340050320.

20. McDermott C, Stock GN. Hospital operations and length of stay performance. Int J Oper Prod Manag. 2007;27(9):10201042. doi:10.1108/01443570710775847.

21. Thomas JW, Guire KE, Horvat GG. Is patient length of stay related to quality of care? Hosp Health Serv Adm. 1997;42(4):489-507.

22. Ashby J, Guterman S, Greene T. An analysis of hospital productivity and product change. Health Aff (Millwood). 2000;19(5):197-205. doi:10.1377/hlthaff.19.5.197.

23. Glick HA, Orzol SM, Tooley JF, Polsky D, Mauskopf JO. Design and analysis of unit cost estimation studies: How many hospital diagnoses? How many countries? Health Econ. 2003;12(7):517527. doi:10.1002/hec.750.

24. Burns LR, Chilingerian JA, Wholey DR. The effect of physician practice organization on efficient utilization of hospital resources. Health Serv Res. 1994;29(5):583-603.

25. Polverejan E, Gardiner JC, Bradley CJ, Holmes-Rovner M, Rovner D. Estimating mean hospital cost as a function of length of stay and patient characteristics. Health Econ. 2003;12(11):935-947. doi:10.1002/hec.774.

26. Langland-Orban B, Gapenski LC, Vogel WB. Differences in characteristics of hospitals with sustained high and sustained low profitability. Hosp Health Serv Adm. 1996;41(3):385-399.

27. Sear AM. Operating characteristics and comparative performance of investor-owned multihospital systems. Hosp Health Serv Adm. 1992;37(3):403-415.

28. Butler TW, Leong GK. The impact of operations competitive priorities on hospital performance. Health Care Manag Sci. 2000;3(3):227-235. doi:10.1023/a:1019057811167.

29. Lagoe RJ, Westert GP, Kendrick K, Morreale G, Mnich S. Managing hospital length of stay reduction: a multihospital approach. Health Care Manage Rev. 2005;30(2):82-92. doi:10.1097/00004010-200504000-00002.

30. Caron A, Jones P, Neuhauser D, Aron DC. Measuring performance improvement: total organizational commitment or clinical specialization. Qual Manag Health Care. 2004;13(4):210-215.

31. Anderson JG, Harshbarger W, Weng HC, Jay SJ, Anderson MM. Modeling the costs and outcomes of cardiovascular surgery. Health Care Manag Sci. 2002;5(2):103-111. 
doi:10.1023/a:1014472731382.

32. Raffiee K, Wendel J. Interactions between hospital admissions, cost per day and average length of stay. Appl Econ. 1991;23(1B):237-246. doi:10.1080/00036849108841068.

33. Shi L. Patient and hospital characteristics associated with average length of stay. Health Care Manage Rev. 1996;21(2):4661. doi:10.1097/00004010-199605000-00007.

34. Brown MP, Sturman MC, Simmering MJ. Compensation policy and organizational performance: The efficiency, operational, and financial implications of pay levels and pay structure. Acad Manage J. 2003;46(6):752-762. doi:10.2307/30040666.

35. Kunders GD, Gopinath S, Katakam A. Hospitals: planning, design, and management. New Delhi: Tata McGraw-Hill Publishing Company; 2001.
36. Rezapour A, Khalaj M. The economic behavior of general hospitals of Iran University of Medical Sciences from 1997 to 2004. J Shahrekord Univ Med Sci. 2006;8(3):11-16.

37. Rezapour A, Asefzadeh S, Ebadifard AF. Calculating of dailypatient hotel cost in hospitals of Qazvin University of Medical Sciences. Teb va Tazkieh. 2009;18(4):8-18. [Persian].

38. McKay $\mathrm{NL}$, Lemak $\mathrm{CH}$, Lovett $\mathrm{A}$. Variations in hospital administrative costs. J Healthc Manag. 2008;53(3):153-166; discussion 166-157.

39. Sadaghiani E. Health care and hospital evaluation standards. Tehran: Jafari Publication; 2005. [Persian].

40. Orendi J. Health-care organisation, hospital-bed occupancy, and MRSA. Lancet. 2008;371(9622):1401-1402. doi:10.1016/ s0140-6736(08)60610-8. 